\title{
GUERNICA: A OBRA, SUA CONTEXTUALIZAÇÃO HISTÓRICA E SUA SIMBOLOGIA PARA OS MOVIMENTOS ARTÍSTICOS E SOCIAIS PELA PAZ, LIBERDADE E DEMOCRACIA
}

\author{
Adriana Silva Maillart* \\ Virgínia Grace Martins de Oliveira**
}

\section{Resumo:}

Pablo Picasso revolucionou seu tempo, quebrando paradigmas em relação à forma de retratar a arte. Uma de suas obras mais célebres foi Guernica, um verdadeiro manifesto de repúdio e resistência ao bombardeiro à cidade basca de mesmo nome e dava indícios de como seria a Segunda Guerra Mundial. O artigo analisa, do ponto de vista da arte, a composição e sintaxe visuais e o contexto histórico da pintura e, do jurídico, a importância da obra como expressão dos movimentos artísticos e sociais pela paz, liberdade e democracia. Adota-se o método dedutivo de abordagem e técnicas bibliográfica e documental de pesquisa.

\section{Palavras-chave:}

Direito e arte; Pablo Picasso; Guernica; Movimentos sociais; liberdade e democracia

\section{GUERNICA: THE PAINTING, HISTORICAL CONTEXT AND ITS SYMBOLISM FOR ARTISTIC AND SOCIAL MOVEMENTS FOR PEACE, FREEDOM AND DEMOCRACY}

\begin{abstract}
:
Pablo Picasso revolutionized his era, breaking paradigms in the way of portraying art. In Guernica, a true manifestation of repudiation and resistance to the bomber against the Basque's city and an example how would be the Second World War. The article analyzes, from art's view, the visual composition and syntax, and the historical painting's context, from the legal point of view, the importance of the work as an expression of artistic and social movements for peace, freedom and democracy. It adopts the deductive method and the bibliographic and documentary research's techniques.
\end{abstract}

Keywords: Law and arts; Pablo Picasso; Guernica; Social movements; freedom and democracy

\section{INTRODUÇÃO}

\footnotetext{
*Pós-Doutora pela Universidade Federal de Santa Catarina (2018). Bacharel em Direito pela Universidade de Passo Fundo (1998) e mestre (2002) e doutora em Direito pela Universidade Federal de Santa Catarina (2007), realizando parte de sua pesquisa na Universidad de Valéncia, Espanha. Desenvolveu pesquisas no Instituto de Relações Internacionais (UFSC) e foi diretora bénévole da Câmara do Comércio belga-luxemburguesa-brasileira em Bruxelas, Bélgica. Professora de Cursos de pós-graduação latu e strictu senso. E-mail:adrissilva@ gmail.com. **Mestre em Direito, com ênfase em Justiça e o Paradigma da Eficiência, pela Universidade Nove de Julho (UNINOVE) 2015. Licenciada em Letras pela Universidade São Francisco (USF)1988. Foi professora de língua portuguesa na rede pública de ensino da cidade de São Paulo. Bacharel em Direito pela Faculdade Anhanguera de Taboão da Serra. E-mail: virginiagrace@gmail.com.
} 
«No, la pintura no está hecha para decorar las habitaciones. Es un instrumento de guerra ofensivo y defensivo contra el enemigo». Pablo Picasso

Pablo Picasso é considerado, por muitos, um dos maiores artistas do século XX, apesar de ser conhecido eminentemente por sua pintura, ele transitou por várias expressões da arte, tais como a escultura, cerâmica, desenho, fotografia e gravura. Ele foi considerado por muitos um gênio e, para outros, um louco. Mas, um ponto inegável, é o fato de que Picasso mudou o curso de retratar a pintura, desconstruindo a pintura para então reconstruí-la.

Uma das suas principais obras é Guernica, que, muito mais que uma representação de arte, foi, como ele próprio menciona, "um instrumento de guerra ofensiva e defensiva contra o inimigo" (ADAMUZ, 2017). Guernica foi considerada um símbolo de resistência, retratando as atrocidades do bombardeamento à cidade basca de mesmo nome, no ano de 1937, e uma forma de enfrentamento às forças nazistas em momento posterior, demonstrando que arte se constitui numa arma potente de combate às injustiças, à guerra e ataques à democracia.

Neste ensaio analisar-se-á a contextualização histórica da obra, descrevendo o período em que está inserida, além da descrição do autor e da obra em si, demonstrando que Guernica perpassou seu tempo e continua até hoje influenciando outros artistas e sendo utilizada como bandeira de movimentos sociais em prol da paz, da liberdade e da democracia.

Enfim, adotando-se os recursos tecnológicos, será feita a leitura da obra para a análise mais detalhada dos elementos empregues pelo autor. Adota-se o método dedutivo de abordagem, com análise formal da obra e seu contexto jurídico, por meio da técnica bibliográfica e documental de pesquisa.

\section{PABLO PICASSO: VIDA DO AUTOR}

Pablo Picasso nasceu em Málaga/Espanha em 25 de outubro de 1881, recebendo o nome de Pablo Diego José Francisco de Paula Juan Nepomuceno María de los Remedios Cipriano de la Santíssima Trinidad Ruiz y Picasso. Era filho de María Picasso y López e José Ruiz Blasco (AMORIM, 2020). Foi seu pai, professor de desenho e de história da arte, quem lhe ensinou o básico da técnica acadêmica e o incentivou em sua vocação artística. Picasso estudou na Real Academía de Bellas-Artes de San Fernando, em Madri, e "antes dos 18 anos 
de idade já fazia parte das fileiras dos autodenominados 'modernistas', artistas e escritores não conformistas" (APPOLINAIRE, 2017, p. 23).

Picasso dividia seu tempo entre Barcelona, Madri e Paris, mas em 1904 se instala definitivamente em Paris, dividindo o famoso Bateau Lavoir com Juan Gris, Van Dongen e outros (FRAZÃO, p. 2020).

Durante a trajetória de Picasso, sua arte passa por diversas fases ${ }^{1}$. Dentre elas, podemos destacar a fase azul (1901-1904), assim como o próprio nome indica, são compostas de pinturas em tons azuis influenciadas pela morte de seu amigo Casagemas, que exprimem sua profunda tristeza e solidão (APPOLINAIRE, 2017, p. 23).

Entre 1905 e 1906, surge a fase rosa, na qual predominam os temas circenses, inspirada pelos saltimbancos do Circo Médrano, revelando o seu momento mais alegre e otimista, em que se encontra apaixonado por Fernande Olivier (BABELIO, 2020).

Durante o outono de 1907, Picasso dedica-se a esculpir estatuetas e esculturas estranhas, influenciado pelas estatuetas africanas de madeira do museu etnográfico do Palais du Trocadéro. Como expõe Guillaume Apollinaire et al, "esta art nègre influenciou seu estilo e especialmente a ideia que ele tinha da representação pictórica. Ao final do ano, nus femininos, tema que se tornara importante para ele, foram assunto de composições de grandes dimensões, como Três Mulheres e Les Demoiselles d'Avignon" (APPOLINAIRE, 2017, p. 23).

A pintura "Les Demoiselles d'Avignon" de 1907 inaugura esta técnica revolucionária, provavelmente inspirada nas artes africanas ou "artes primitivas". Esta obra dá início ao que foi denominado de movimento cubista, quebrando as leis tradicionais da pintura ocidental; os objetos representados são "achatados" na tela para que todos os seus ângulos sejam visíveis simultaneamente (LADIC, 2020).

Guillaume Appolinaire et al (2017, p. 23), explicando a criação desta nova técnica, expõe que,

Trancado em seu estúdio, trabalhando a madrugada toda, como era seu hábito, Picasso concentrava-se de modo obstinado em reaprender, mudando seu gosto, treinando de novo seus sentimentos pessoais. Existe uma razão que explica por que quase todas as suas obras de 1907 têm o caráter simples de exercícios em sala de aula: estudos de nus, bustos, cabeças, naturezas-mortas; há também uma razão para ele ter produzido todas essas suas obras "acadêmica" sem modelos, a partir das

\footnotetext{
${ }^{1}$ Nas palavras de Guillaume Appolinaire et al (2017, p. 24), "Pablo Picasso promoveu sua revolução vivendo, por assim dizer, a vida de vários artistas, atravessando várias fases de crescimento, vários períodos”.
} 
esculturas africanas e da sua imaginação. Picasso buscava aprimorar o poder de expressão, mas não necessariamente no assunto, no tema ou no objeto, e sim nas linhas, nas cores, formas e pinceladas tomadas em seu sentido independente, na própria energia do gesto pictórico. Grifou-se.

Segundo Susie Hodge (2019, p. 22), “os cubistas representavam pontos de vistas simultâneos em suas obras. Com isso criava mais ângulos e planos do que em pinturas tradicionais a partir de um único ponto de vista, as obras geralmente pareciam feitas de formas geométricas, o que inspirou o nome do movimento". Acrescenta ainda que, "numa tentativa de representar o mundo de maneira mais franca, os cubistas abandonaram a perspectiva linear que vinha sendo utilizada desde o renascimento para retratar profundidade e distância" (HODGE, 2019, p. 22).

Inspirados pela exposição retrospectiva das obras de Cézanne, em 1906, Pablo Picasso e George Braque começam a retratar objetos, pessoa e lugares a partir de vários pontos de vista ao mesmo tempo, renunciando à tradição artística e criando ilusões a partir de ângulos fixos. Eles desenvolvem o cubismo ${ }^{2}$ em 1907-1908, acreditando que com esta nova técnica ofereceriam ao "espectador visões do mundo mais exatas do que as pretensas representações de tridimensionalidade" (HODGE, 2019, p. 22).

Em 1912, a galeria La Boétie, em Paris, expõe quase 200 quadros qualificados como cubistas, entretanto, nem as obras de Picasso nem as de Braque estavam presentes. Dan Franck (2017, p. 192) explica que:

Essa recusa obstinada a se misturar com os que reivindicam, em alto e bom tom, um
título que lhes pertence de direito marca o desprezo que eles têm por aqueles que
Braque chama de "cubistores". Picasso, ainda mais direto, não hesita em afirmar:
"Não existe cubismo". O que é tão provocador quanto a frase que ele iria pronunciar
sobre a arte negra nos anos 1920: "Arte negra? Nunca ouvi falar..." E que traduz,
além do desejo de se distinguir, seu desprezo pelas escolas e teorias.

No auge do cubismo, Braque e Picasso afastam-se das discussões e deixam elas para seus aliados, como Max Jacob, por exemplo, que afirmava que, “o cubismo na pintura é a arte de trabalhar o quadro por ele mesmo, fora do que ele representa, e de dar à construção geométrica o primeiro lugar, criando apenas uma alusão à realidade" (FRANCK, 2017, p. 194). Já doutor Artault, de Vevey explicava o cubismo como um fenômeno patológico, afirmando que:

\footnotetext{
2 "Como para o impressionismo, o nome cubismo foi a princípio usado zombeteiramente, cunhado por um crítico numa exposição de 1908, mas permaneceu" (HODGE, 2019, p. 22).
} 
Basta, na verdade, observar, como os olhos semicerrados, um quadro cubista para encontrar ali, em meio a zigue-zagues e a vislumbres decrescentes, as deformações e as formas fugidias dos objetos, características das irisações monocromáticas e intermitentes, desse acidente que chamamos de escotoma cintilante, o sintoma mais frequente da enxaqueca oftálmica (PARIS JOURNAL, 1914).

Em outras palavras, para a medicina, "Braque e Picasso são doidos"! (FRANCK, 2017, p. 195). Opinião esta reforçada por Léon-Paul Fargue ${ }^{3}$, que acreditava que os cubistas sofriam de uma crise de intelectualidade, eram semi-instruídos e possuíam a cabeça fraca demais para o aprendizado (FRANCK, 2017, p. 195-196). "Não há dúvida de que Pablo Picasso virou de cabeça para baixo a arte e a forma de entendê-la", como aduz Sylvia Ladic (2020).

Apesar das primeiras reações serem críticas, ao longo do tempo, suas obras começaram a ter prestígio e, em linhas gerais, pode-se afirmar que Picasso é considerado, por muitos, o maior artista do século XX, exprimindo sua arte não só na pintura, mas também na escultura, cerâmica, desenho, fotografia e gravura, tendo como uma das suas mais importantes obras, a pintura sobre tela: Guernica.

\section{GUERNICA: ANÁLISE DA OBRA}

A análise da obra intitulada Guernica se consubstancia em expor a contextualização histórica no qual a obra está inserida, bem como, expor uma análise da obra em si, com o fim de demonstrar que Guernica influenciou e continua a influenciar nos tempos atuais outros artistas, sendo vista e utilizada como bandeira de luta dos movimentos sociais pela paz, liberdade e democracia.

\subsection{Contextualização histórica}

Quando pintou Guernica, Picasso já era um pintor reconhecido e famoso. Morando em Paris, foi contactado pelo governo espanhol para realizar um quadro que seria exposto no Pavilhão espanhol da Exposição Universal da cidade luz, de $1937^{4}$. Enquanto buscava

\footnotetext{
3 "Léon-Paul Fargue, (born March 4, 1876, Paris—died Nov. 25, 1947, Paris), French poet and essayist whose work spanned numerous literary movements" (EDITORS OF Encyclopaedia Britannica, 2020).

4 "O Pavilhão Espanhol atraiu a atenção pois a exposição aconteceu ao mesmo tempo que a Guerra Civil Espanhola. O pavilhão foi construído pelo arquiteto espanhol Josep Lluis Sert, e financiado pelo governo
} 
inspiração para a criação de uma obra para envio à exposição, no dia 26 de abril daquele ano, "a realidade da guerra se impôs de forma trágica como tema central, quando a pequena cidade de Guernica, no País Basco, foi bombardeada pela Luftwaffe alemã, por ordem de Adolf Hitler, (em apoio ao general Francisco Franco durante a guerra civil espanhola)" (AMORIM, 2020). Como explana Tiago Cordeiro (2020):

\begin{abstract}
Guernica não estava na linha de frente do conflito, mas era um ponto estratégico. Primeiro, por sua localização ao norte da Espanha, nos arredores de Bilbao. Segundo, por ser uma área de tradição na fabricação de armas - as indústrias, não atingidas pelo bombardeio, seriam usadas pelos nacionalistas. Mas, principalmente: a cidade era a alma do País Basco. Abriga a Gernikako Arbola, a árvore de Gernika (é assim que os locais escrevem o nome da cidade), um carvalho que simboliza os desejos de autonomia do povo basco - e a oposição à independência dos bascos, catalães e galegos era um ponto nevrálgico da ideologia nacionalista. Guernica seria rendida ao general Franco dias depois, em 29 de abril. Uma das muitas evidências de que o ataque foi planejado como um ato político é o fato de nenhum sobrevoo de reconhecimento ter sido realizado: os aviões simplesmente surgiram no meio da tarde. Nenhum era espanhol: a ação foi conduzida por dois aviões Heinkel He 111, um Dornier Do 17 e outros 18 Junkers Ju 52, pertencentes à Legião Condor, da Alemanha nazista, e três modelos Savoia-Marchetti SM.79 da Aviazione Legionaria, da Itália fascista.
\end{abstract}

O bombardeamento ${ }^{5}$, que durou menos de 3 horas, fez imediatamente 300 mortos e milhares de feridos e foi visto como um teste para os ataques aéreos que seriam realizados na Segunda Guerra Mundial (1939-1945).

Guernica (o quadro) retrata as atrocidades do bombardeamento à cidade basca de mesmo nome e é considerada um símbolo de resistência ${ }^{6}$. Tanto que, em 1985, uma

republicano e incluiu a famosa pintura Guernica, de Pablo Picasso, uma mostra dos horrores da guerra, a escultura Fonte de Mercúrio, de Alexander Calder e a pintura Pastor Catalão em revolta, de Joan Miró. Dois outros pavilhões notáveis foram os da Alemanha Nazista e da União Soviética. A organização da feira colocou os dois pavilhões muito próximos, em direções opostas da Torre Eiffel. Adolf Hitler queria desistir da exposição, mas seu arquiteto Albert Speer convenceu-o a participar, após mostrar seus planos do pavilhão. Speer depois revelou, em sua autobiografia, que tinha dado uma olhada clandestina nos planos do pavilhão soviético e desenhou o pavilhão alemão a fim de representar o anticomunismo" (WIKIPEDIA, 2020).

5 “ O dia 26 de abril de 1937 foi uma segunda-feira. A cidade de Guernica, no norte da Espanha, estava cheia de vida: até então ela permanecera praticamente intocada pela Guerra Civil Espanhola, que grassava desde o ano anterior. Entretidos em seus afazeres, os 5 mil habitantes entravam e saíam de suas casas, feitas de estruturas e galerias em madeira e cobertas de telhas. No fim da tarde, começaram os bombardeios aéreos isolados. Por volta das 6h30, veio o ataque principal dos aviões alemães, em ondas sucessivas. Segundo um diário de guerra da época, a esta altura a fumaça já era tanta que não se distinguiam mais os alvos - casas, pontes ou arrabaldes - e os pilotos dos 50 bombardeiros da Legião Condor atiravam sua carga mortal indistintamente. Calcula-se que, ao todo, 22 toneladas de explosivos foram lançados [sic] sobre aquela cidade do País Basco, entre pequenas bombas incendiárias e bombas de 250 quilos. A rede de canalização d'água foi rapidamente destruída, e assim o fogo teve todo o tempo para alastrar-se e consumir Guernica. O diário de guerra conclui: "O tipo de construção das casas fez com que a destruição fosse total. Ainda se veem os buracos das bombas na rua. Simplesmente fantástico" (GERICKE, 2020). 
reprodução de Guernica em tapeçaria foi colocada na entrada do Conselho de Segurança da ONU em Nova Iorque, para relembrar a todos sobre os horrores da guerra (UNITED NATIONS, 2020).

\subsubsection{A obra}

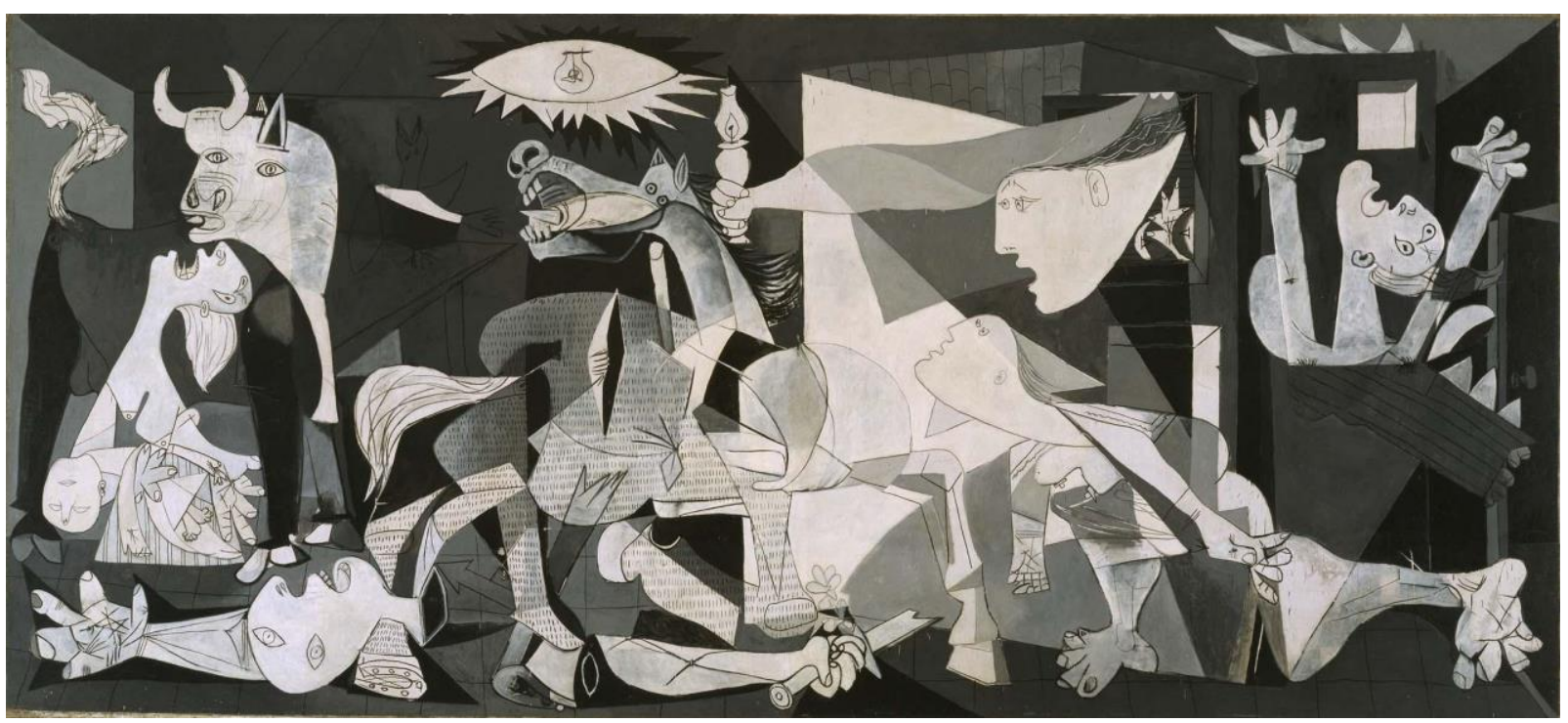

Guernica - Pablo Picasso - Fonte: https://static5.museoreinasofia.es/sites/default/files/obras/DE00050.jpg ${ }^{7}$

"Guernica" foi exposta pela primeira vez no pavilhão espanhol da Exposição Universal de Paris em julho de 1937. Depois da Exposição de Paris, o quadro foi exibido em Oslo, Copenhagen, Estocolmo e Gotemburgo, Londres, Leeds, Liverpool e Manchester (LUSA, 2020). O mural foi adquirido pelo Estado Espanhol em 1937, mas com a eclosão da Segunda Guerra Mundial, Picasso decidiu que a pintura ficaria sob custódia do Museu de Arte Moderna (MoMA) de Nova York, até o fim do conflito bélico ${ }^{8}$. Em 1958, Picasso renovou o

\footnotetext{
6 "Since 1937, the painting has been able to express, visualise and connect different historical and political processes, rising up in the fight against the exploitation of human life and civil rights in states' geopolitical strategies, in the condemnation of racist and patriarchal structures, and against economic interests above the common good which determine who can live and die" (MUSEO NACIONAL REINA SOFIA, 2020).

${ }^{7}$ Título da obra: Guernica

Artista: Pablo Picasso (1881 - 1973)

Categoria: Pintura

Técnica: Óleo sobre tela

Data da criação: 1937 (1 de maio - 4 de junho, Paris)

Dimensão: 349,3 x 776,6 cm

8 “Em 1939, antes do início da II Guerra Mundial, o quadro foi enviado para os Estados Unidos, onde foi mostrado no Museu de Arte Contemporânea de São Francisco, primeiro, e no Museu de Arte Moderna (MoMA),
} 
empréstimo do quadro ao MoMA por tempo indeterminando, condicionando sua entrega à Espanha ao restabelecimento das liberdades democráticas naquele país. A obra regressou ao Estado espanhol apenas em 1981 (após a morte de Picasso e de Franco), chegando em Madri sob forte vigilância e ficou no então novo anexo do Museu do Prado, há dois quarteirões do parlamento espanhol, palco de uma tentativa fracassada de um novo golpe militar em fevereiro daquele ano. Em 25 de outubro do mesmo ano, Guernica foi exposta ao público, protegida por uma espessa camada de vidro à prova de bala, na ocasião do $100^{\circ}$ aniversário do nascimento de Picasso (HISTORY, 2020).

Em 1992, Guernica ingressou ao acervo do Museu Nacional Reina Sofia, situado em Madri, onde continua exposta atualmente na sala 206.06 e registrada sob o ${ }^{\circ}$ DE00050 do mencionado Museu (MUSEO NACIONAL REINA SOFÍA, 2020).

\subsubsection{Composição de cores e formas}

Picasso adota na obra o acromatismo e monocronismo utilizando-se do preto, do branco e dos tons de cinza em sua criação. Na análise das cores, deve-se destacar que o preto e branco, também são consideradas cores complementares ${ }^{9}$.

Como expõe Ana Letícia Guimarães Garcia (2020, p. 54):

O esquema acromático envolve o uso de tons localizados na paleta tomada entre o branco e o preto. É chamado de acromático por utilizar cores consideradas não cromáticas, por não estarem presentes no círculo cromático. Nesse esquema de combinações de cores estão presentes o branco, o preto e os cinzas intermediários.

A escolha pelo uso destas cores nos remete a sobriedade do momento vivido, remetem às cinzas e à fumaça causadas pelo bombardeiro, trazendo à tona o lado negativo despertado por estas cores, que segundo Max Lüscher, inspiram o desânimo, depressão, hibernação, falta de energia (cinza) e opressão, frieza, ameaça e angústia (preto) (FRASER; BANKS, 2013, p. 49). Para alguns, as cores utilizadas na tela também podem ser influência das cores do jornal por meio do qual Picasso ficou sabendo da notícia do bombardeio

de Nova Iorque, mais tarde, instituição onde se manteve até 1981, depois de breves passagens por cidades como Chicago e Filadélfia, e pelo Brasil, na década de 1950" (LUSA, 2020).

${ }^{9}$ Segundo Ana Letícia Guimarães Garcia, "Quando o preto faz limite com o branco e o branco com o preto, cada um parece mais intenso no limite com seu contrário do que na parte do meio de sua própria área. No círculo cromático, as complementares encontram-se em posições linearmente opostas" (GARCIA, 2020, p. 54). 
(LADIC, 2020). Inclusive, ao se analisar o cavalo exposto na obra, ele remete a tipografia de um jornal. Guillaume Appolinaire et al (2017, p. 28), reforça esta ideia, ao explicar que, “de início, Picasso colocara toques de cor na obra; o branco e preto da versão final deve ter sido inspirado pelas fotos da guerra (particularmente as de Robert Capa)".

Para Graça Proença (2014, p. 254), o uso da monocromia já era uma tendência cubista que, "trabalharam com poucas cores - preto, cinza e alguns tons de marrom e ocre -, já que o mais importante para eles era definir um tema e apresentá-lo de todo os lados simultaneamente". Isso porque, para eles, “a própria cor não deve se adaptar a fenômenos passageiros, como a luz, o ângulo, o tempo, elementos que traduzem a irrupção do mundo exterior; ela deve inscrever o objeto naquilo que ele tem de durável. Braque [dizia]: 'Não preciso mais do sol, levo a luz comigo"” (FRANCK, 2017, p. 182).

Em relação ao movimento artístico, o quadro pertence ao movimento cubista com traços de surrealismo. Como típico do cubismo, a perspectiva linear não é empregue, pois conforme Graça Proença (2014, p. 254), essa nova maneira de pintar "significava, em suma, o abandono da busca da ilusão da perspectiva ou das três dimensões dos seres, tão perseguidos pelos pintores renascentistas".

Braque e Picasso, naquele momento histórico, trouxeram o debate sobre a teoria da percepção, defendendo que só é possível ter noção de um objeto após vê-lo e senti-lo sob todas as perspectivas (PARRAGON BOOKS, 2012, p. 406). Guillaume Appolinaire et al (2017, p. 28) também ressaltam que: “outra característica da obra (Guernica) era uma das principais expressões do movimento cubista: não levar em conta a distinção entre a visão frontal e a visão de perfil dos seus temas - o espectador vê o assunto ao mesmo tempo a partir de diferentes ângulos", baseado em uma composição piramidal, tendo como cume desta pirâmide a luz (da lâmpada e da lamparina) que convergem ao centro/topo do quadro. Para alguns, a lâmpada seria um símbolo de esperança (LADIC, 2020); para outros, remete às bombas lançadas no ataque à cidade de Guernica.

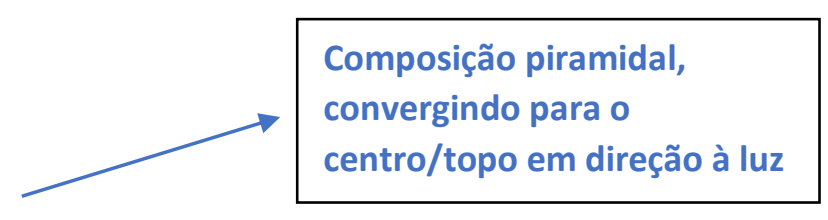




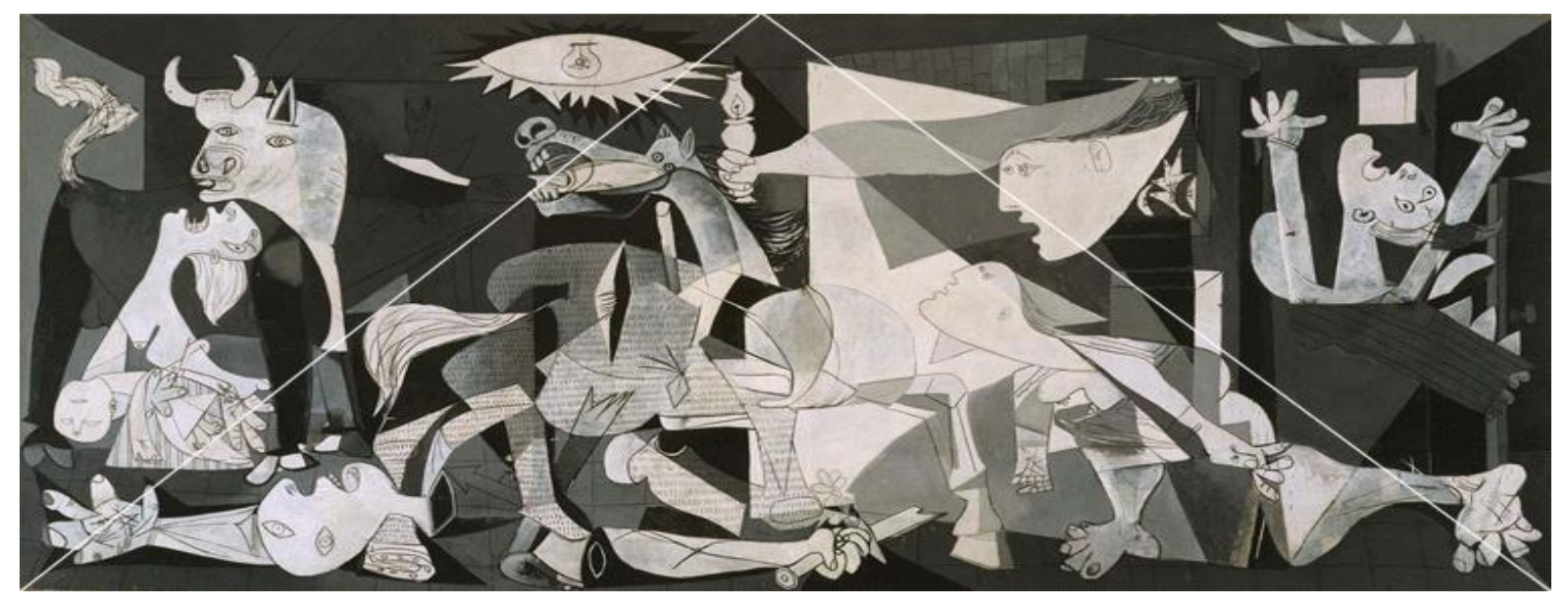

\subsection{Leitura da obra: a mensagem por detrás da imagem}

Antes de fazer uma leitura sobre os símbolos da obra Guernica, deve-se analisar qual era a perspectiva do autor em relação à pintura. Investigando-se qual era a intenção de Picasso ao escolher certos elementos, tem-se a informação de Picasso só teria mencionado algo a respeito do Touro, que, para ele, representaria a brutalidade e a escuridão, e sobre o cavalo, que representaria o povo espanhol. Teria ele acrescentado que: "Não cabe ao pintor definir os símbolos. Caso contrário, seria melhor se ele os escrevesse com tantas palavras. O público que olha para a imagem deve interpretar os símbolos como os entende" ${ }^{\text {" }}$. Sendo assim, aqui far-se-á uma análise subjetiva, como observadora da obra, e uma análise crítica de estudiosos da arte.

\footnotetext{
10 "It isn't up to the painter to define the symbols. Otherwise it would be better if he wrote them out in so many words. The public who look at the picture must interpret the symbols as they understand them" [Tradução livre] (ROBINSON, 2020).
} 


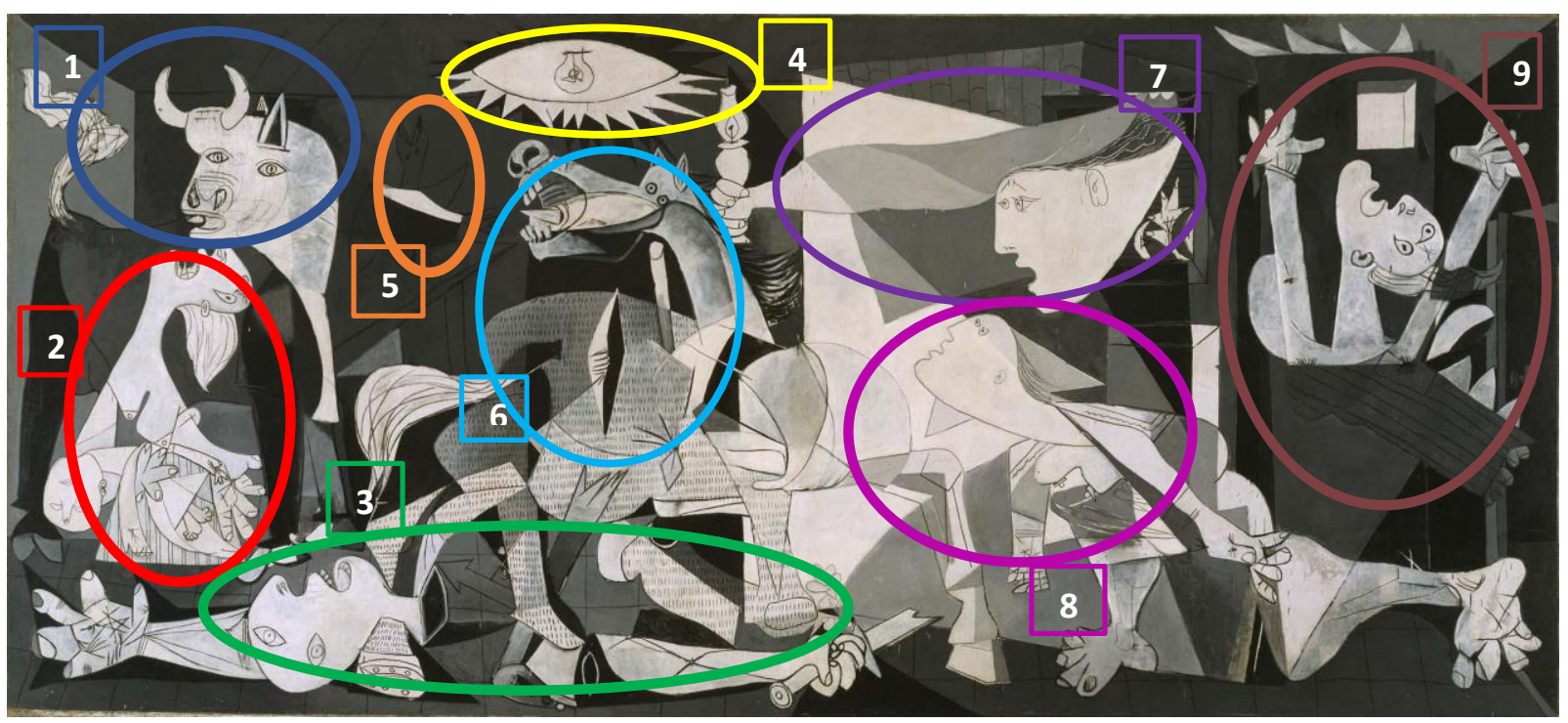

1) TOURO

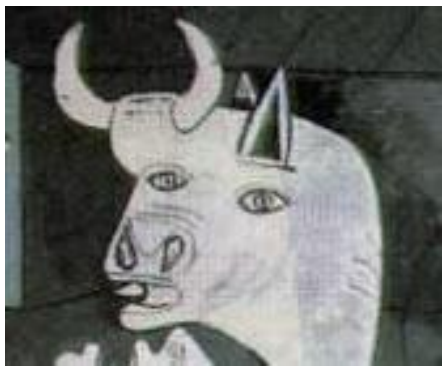

Como mencionado anteriormente, Picasso teria dito que o touro simboliza "a brutalidade e as trevas" do fascismo. Mas alguns, como é o caso Guillaume Appolinaire et al (2017, p. 28), acreditam que a representação do touro em Guernica, reportaria que, "a tragédia da pequena cidade é estendida a toda a Espanha ao incluir o touro, símbolo da obsessão do país pelas corridas de touros naquela época [...]”.

Vale à pena ressaltar que, nas corridas de touro (toureadas), o touro é visto como um animal forte, selvagem, livre e errante, não sujeito à disciplina humana. Desta forma, ele é visto como um perigo para os povos primitivos, concebendo-o como um inimigo que disputava o domínio da terra (RUBIO, 2020). Daí à tradição das toureadas espanholas que, como explica, "não é vista [a toureada] como uma crueldade, ela é vista como um milagre é a representação do triunfo da vida sobre a morte. A morte é algo perecível, que destrói a existência, por isso é tão valioso vencer em uma tourada, o vencedor não só vence a batalha, vence a morte" (MOZER, 2011, p. 38). Talvez daí venha o simbolismo do touro retratado em Guernica, retratando-o como o inimigo, como a brutalidade e tenebrosos algozes ao qual foi submetido os cidadãos de Guernica e o povo espanhol, como um todo.

\section{2) MULHER COM FILHO NOS BRAÇOS}




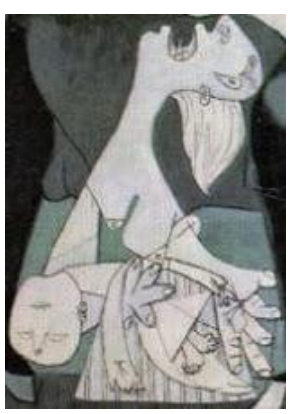

Esta imagem nos remete à Pièta, a Virgem Maria que carrega Jesus Cristo nos braços, eternizada por diversos artistas, dentre eles, Michelangelo, como se pode observar na imagem ao lado. Este elemento da obra de Picasso retrata todos os horrores do bombardeio, que tocou vítimas inocentes. Vale relembrar que, o bombardeio se deu no momento da realização de uma feira na cidade de Guernica, onde grande parte de seus participantes eram mulheres e crianças. O seio desnudo da

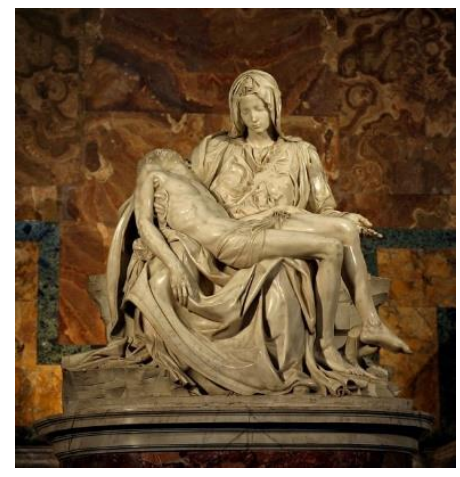

Figura 1Michelangelo, Pieta, c. 1498-1500, mármore senhora evoca a maternidade.

\section{3) SOLDADO FERIDO}

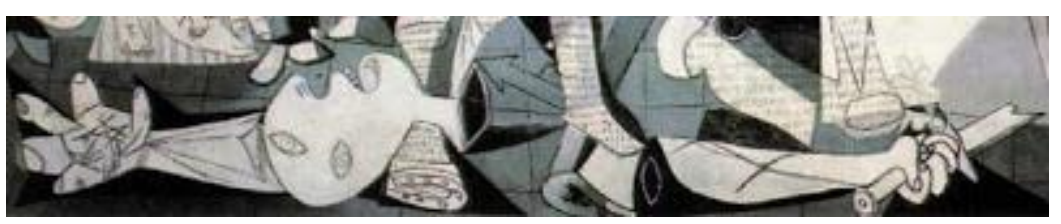

O corpo está em pedaços demonstrando os horrores da guerra e, em particular, dos bombardeios. Para alguns, a espada quebrada representa o exército republicano, cuja a resistência está destruída (LADIC, 2020).

\section{4) LÂMPADA}

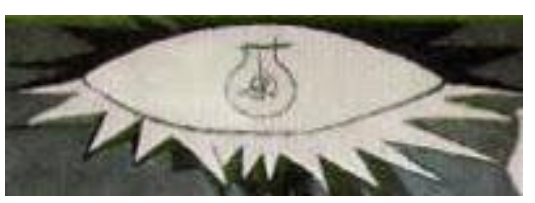

Esta figura está no topo quase no centro e pode ter diversas interpretações: uma de mais conotação negativa, fazendo uma alusão às bombas que foram lançadas sobre as vítimas inocentes em Guernica; ou, outra menos negativa, que seria a representação de um olho, que evoca ver a verdade (talvez o olho de Picasso, que denuncia a verdade trágica (COLLÉGE DU CHINCHON MONTARGIS, 2020).

\section{5) POMBA}

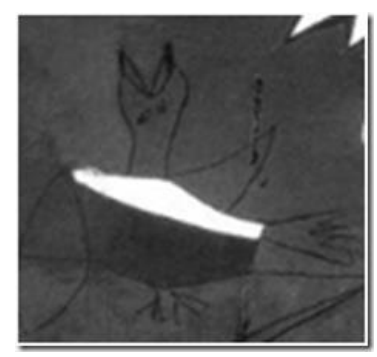

A pomba é a representação da paz, entretanto, na tela de Picasso, ela está na obscuridade, talvez esperando seu momento de voltar à cena. 


\section{6) CAVALO}
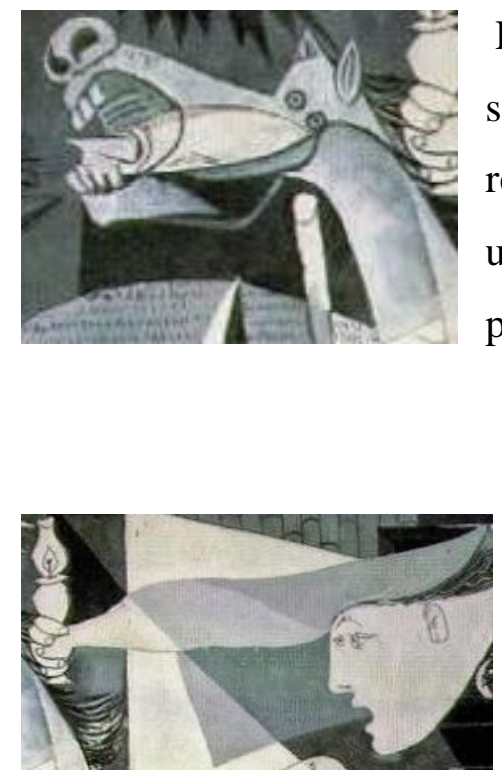

2020).

Este é outro elemento do quadro que, Picasso teria mencionado o significado. Segundo ele, o cavalo representa o povo. Ele é representado ferido (lança, ferida de lado). Ele relincha de dor, uma vítima inocente dos terrores da guerra: uma representação do povo martirizado (LADIC, 2020).

\section{7) PESSOA COM LAMPARINA}

Para Guillaume Appolinaire et al (2017, p. 28), a lamparina simbolizaria a justiça. Para outros, poderia ser a esperança ou a liberdade (fazendo uma alusão à tocha da estátua da liberdade, por exemplo (COLLÉGE DU CHINCHON MONTARGIS,

\section{8) MULHER COM A PERNA FERIDA}

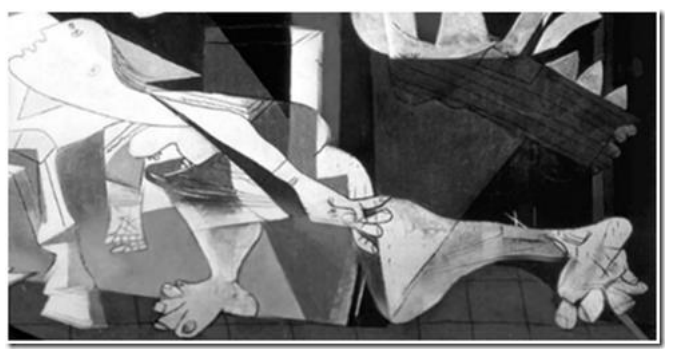

Percebe-se a dor, pois a perna está muito deformada e a mulher parece colocar sua mão no local do ferimento. Ela caminha em direção à luz no centro da tela, apesar de sua lesão. Pode representar o povo inocente e ferido, que não perde a esperança e segue em frente.

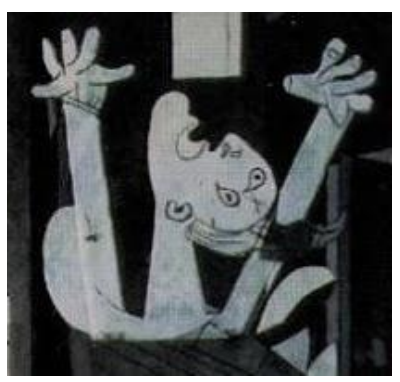

9) MULHER COM CASA EM CHAMAS

Sofrimento e desespero, braços erguidos em direção ao céu. Alguns críticos, veem a influência de Goya neste elemento, reportando a 
imagem do homem de braços abertos no quadro "El tres de mayo (conforme imagem ao lado ${ }^{11}$. Segundo Simone Martins (2020), esta "é uma das imagens mais memoráveis da desumanidade do homem para com o homem". Retrata a execução, em três de maio, de centenas de rebeldes e de muitas outras pessoas que eram apenas observadores dos inocentes, em reação ao levante dos cidadãos de Madri, em 2 de maio de 1808, contra o exército de Napoleão, que havia ocupado a Espanha.

\section{GUERNICA: UMA JANELA PARA O FUTURO}

Observa-se que Guernica tanto por sua conotação histórica e motivação quanto por sua sintaxe artística, teve como intuito contestar as atrocidades ocorridas na cidade de Guernica e exprimir pela arte (por meio de suas cores, formas e elementos), a dor, a treva e a brutalidade promovidas por governos autoritários, que extirpam de suas vítimas inocentes a paz e, como foi demonstrado pelo decorrer da História, sua liberdade e democracia.

Guernica, com seu simbolismo, ultrapassou seu tempo e tornou-se inspiração para vários artistas e uma bandeira para os movimentos sociais contra a guerra e demais atrocidades, bem como pela luta pela paz, pela liberdade e pela democracia. Benjamin Hannavy Cousen, inclusive ressalta que, como "personificação" da memória cultural, Guernica "tem um peso de dever contínuo" e é "uma obra que se move para o futuro". (LESSER, 2011, p. 103)

Como aponta o Museo Nacional Reina Sofía: "a realização da pintura foi originalmente uma resposta à violência fascista que deu início a uma nova forma de guerra, mas foi em torno da Guerra do Vietnã, com as ações da Art Workers 'Coalition no Museu de Arte Moderna de Nova York, quando começou para ganhar impulso como ícone político" (MUSEO NACIONAL REINA SOFIA, 2020).

De tal forma que:

No século XXI, cidadãos de todo o mundo se apropriaram de Guernica em texto e imagem para expressar pesar por eventos trágicos ainda relacionados à guerra, mas também em referência a outros tópicos de tragédia, como genocídio e desastres naturais. No momento, Guernica é amplamente elogiado, lembrado e utilizado em novas obras de arte por artistas contemporâneos para comentar sobre eventos

\footnotetext{
${ }^{11}$ Figura Erro! Apenas o documento principal - Goya, el tres de mayo en Madrid, óleo em tela, 1814 Fonte: https://www.museodelprado.es/coleccion/obra-de-arte/el-3-de-mayo-en-madrid-o-los-fusilamientos/5e1774092993-4240-97fb-847a02c6496c
} 
desastrosos, mais recentemente, incluindo o derramamento de óleo da $\mathrm{BP}$ e o conflito na Líbia. (LESSER, 2011, p. 103)

Exemplo desta "apropriação" foi a exposição fotográfica de Schommer, denominada Guernica movido, para comemorar um ano dos atentados aos trens de Madri em 11 de março de 2004 e aos ataques ao World Trade Center em 11 de setembro de 2001. Segundo Lesser (2011, p. 104), "ambos os ataques se alinham perfeitamente com o ataque Guernica de 1937, especialmente no sentido de que os ataques tinham como alvo civis inocentes". Ainda ressalta que,

[...] assim como o ataque a Guernica foi planejado para um dia de mercado, quando a maioria dos civis estaria na cidade, os ataques de Nova York e Madrid foram planejados para horas de pico, quando a maioria das pessoas estaria dentro ou ao redor do World Trade Center, no caso de Nova York, e nos trens urbanos, no caso de Madrid. (LESSER, 2011, p. 104)

Em 2003, a artista Sophie Matisse também combinou a obra Guernica com o estilo artístico do seu bisavô Henri Matisse, para retratar a primeira grande catástrofe do século XXI para os cidadãos estadunidenses, o 11 de setembro (LESSER, 2011, p. 107).

Em 2009, Goshka Macuga, uma artista polonesa radicada em Londres, fez uma exposição de grande escala incorporando a história de Guernica para comentar a função da obra como pano de fundo para a política (LESSER, 2011, p. 112).

O projeto Kids Guernica (lançado em 1995), como o próprio nome faz subentender, teve inspiração na obra de Picasso, e compreende um projeto internacional de arte infantil para criar um mural da paz em uma tela do tamanho de "Guernica" (3,5m x 7,8m). Este projeto tem como objetivo exprimir o espírito de paz e conectar pessoas, de tal forma que mais de 160 pinturas da paz já foram criadas em 40 países do mundo (CREATIVE RESISTANCE, 2021).

Como informa o Museu Nacional Reina Sofia (MUSEO NACIONAL REINA SOFIA, 2020), fragmentos, figuras, expressões, variações e réplicas da tela pintada por Picasso são utilizadas como bandeira, toda vez que ocorre um surto de violência contra civis. Guernica tornou-se progressivamente um ícone da paz, utilizado de forma recorrente em âmbitos não institucionais, e não apenas em espaços artísticos, mas também em espaços de protesto, manifestações coletivas e em áreas geográficas díspares. 
Estas manifestações de retomada e revisão sugerem que os indivíduos/cidadãos e a sociedade coexistem e formulam movimentos de reivindicação e enfrentamento ao sistema já estabelecido organizado pelo Estado. Movimentos estes que possuem a capacidade de pressionar os Três Poderes da República, que se mobilizam de acordo com suas competências, para atender às demandas por novos direitos e pela efetivação dos direitos já positivados. Nessa direção, Bobbio esclarece (2004, p. 203) que,

[...] sem direitos do homem reconhecidos e efetivamente protegidos não existe democracia, sem democracia não existem as condições mínimas para a solução pacífica dos conflitos que surgem entre os indivíduos, entre grupos e entre as grandes coletividades tradicionalmente indóceis e tendencialmente autocráticas que são os Estados.

Dessa forma, pode-se inferir, portanto, que os movimentos sociais e artísticos assumem grande importância, pois a luta envolve principalmente, efetivação, preservação de direitos e a preservação da própria democracia, mesmo num Estado Democrático de Direito, pois como assinala Bobbio, os Estados possuem uma tendência autocrática.

E neste âmbito, Guernica cumpre sua função, pois tornou-se uma bandeira destes movimentos sociais, que, por sua vez, são importantes instrumentos na aclamação pelo restabelecimento dos Direitos lesionados, mas também pela reinvindicação por novos Direitos. Pois, como Campello e Silveira asseveram (2011, p. 91), “[...] o direito deve refazerse permanentemente face à mobilidade social".

Esse refazimento constante do Direito deve ter um olhar atento às influências da "participação invisível" dos movimentos sociais ou "grupos de pressão", pois analisando-se as considerações de Bonavides (2018, p. 462), estes grupos pertencem ao âmbito informal, mas possuem um relevante papel na luta pela efetivação e preservação de direitos.

\section{CONSIDERAÇÕES FINAIS}

O crítico de arte Robert Rosenblum, analisando a obra, explica que: "ela equivale a uma imagem do fim do mundo, sobretudo do mundo moderno, como o conhecemos. [...] Assim é o quadro Guernica: da forma mais impressionante e poderosa, ele anuncia a mensagem da guerra, do potencial destrutivo do século 20" (GERICKE, 2020). Mas num 
contraponto, também foi um símbolo de resistência, utilizada até hoje para repudiar a violência, o racismo e todas as formas de agressões e discriminações.

Sem dúvida, a obra de Picasso foi um ato de resistência diante das atrocidades da guerra e um grito em prol da restituição da democracia, de tal forma que condicionou a ida da obra pra Espanha quando houve o restabelecimento do Estado democrático de Direito. Infelizmente, isto apenas ocorreu depois de sua morte, mas não se pode negar a importância daquele momento histórico em honra das vítimas da guerra, da luta contra o fascismo e da restauração das liberdades democráticas.

A melhor conclusão a respeito da obra, entretanto, vem nas palavras do próprio Picasso, em resposta a Otto Abetz, embaixador do regime nazista em Paris, que, diante de uma foto do quadro Guernica, teria supostamente perguntado, um pouco indignado, durante uma visita à sua oficina: "Você fez isso?", e Picasso teria respondido: "Não... foi você"12. Isto resume o intento da obra e do espírito do autor e o porquê de Pablo Picasso ser considerado um dos maiores artistas do século XX e o porquê de Guernica continuar sendo, até hoje, um símbolo da busca pela paz, liberdade e democracia e fonte de inspiração para outros artistas.

\section{REFERÊNCIAS}

ADAMUZ, José Alejandro. 80 AÑOS DEL 'GUERNICA'. National Geographic online. 5 abr. 2017. Disponível em: https://viajes.nationalgeographic.com.es/a/80-anosguernica_11362. Acesso em: 4 abr. 2021.

AMORIM, Claudia Peluffo de. Pablo Picasso revolucionou arte do século XX com produção volumosa e genial. Disponível em: https://acervo.oglobo.globo.com/emdestaque/pablo-picasso-revolucionou-arte-do-seculo-xx-com-producao-volumosa-genial22539297\#ixzz6YnOmgbN5. Acesso em: 22 set. 2020.

APPOLINAIRE, Guillaume; EIMERT, Dorothea; PODOKSIK, Anatoli. Trad. Gil Reyes. Cubismo. São Paulo: Folha de São Paulo, 2017.

BABELIO. Fernande Olivier. Disponível em: https://www.babelio.com/auteur/FernandeOlivier/106474. Acesso em: 25 set. 2020.

BOBBIO, Norberto. A era dos direitos. 9. ed. Rio de Janeiro: Elsevier, 2004.

BONAVIDES, Paulo. Ciência política. 25. ed. São Paulo: Malheiros, 2018.

12 LADIC, Sylvia. Analyse d’oeuvre: Guernica de Pablo Picasso. Disponível em: <http://e-cours-artsplastiques.com/analyse-doeuvre-guernica-de-pablo-picasso/>. Acesso em: 21 de set. 2020. 
CAMPELLO, Lívia Gaigher Bósio; DA SILVEIRA, Vladmir Oliveira. Cidadania e direitos humanos. Revista Interdisciplinar de Direito, [S.1.], v. 8, n. 01, p. 87-104, dez. 2011.

Disponível em: http://revistas.faa.edu.br/index.php/FDV/article/view/320. Acesso em: 26 mar. 2021.

COLLÉGE DU CHINCHON MONTARGIS. Préparation à l'epreuve d'Histoire des Arts. Disponível em: http://clg-du-chinchon-montargis.tice.ac-orleanstours.fr/php5/IMG/pdf/3e_HidA_exemple_Guernica_Cours_Complet.pdf. Acesso em: 05 out. 2020.

CORDEIRO, Tiago. 83 anos do terror em Guernica, um marco da Segunda Guerra Mundial. 24 abr. 2020. Disponível em:

https://aventurasnahistoria.uol.com.br/noticias/reportagem/historia-segunda-guerrabombardeio-de-guernica.phtml. Acesso em: 02 abr. 2021.

CREATIVE RESISTANCE. Kids Guernica. Disponível em:

http://creativeresistance.org/kids-guernica/. Acesso em: 02 abr. 2021.

EDITORS OF Encyclopaedia Britannica. Léon-Paul Fargue. Disponível em: https://www.britannica.com/biography/Leon-Paul-Fargue. Acesso em: 25 set. 2020.

FRANCK, Dan. Paris boêmia: a vida agitada em Paris no início do século XX e a grande revolução da arte moderna. Trad. Hortencia Santos Lencastre. Porto Alegre: L\&PM, 2017.

FRASER, Tom; BANKS, Adam. O guia completo da cor. 2. ed. São Paulo: Senac, 2013.

FRAZÃO, Dilva. Pablo Picasso. Disponível em: https://www.ebiografia.com/pablo_picasso/. Acesso em: 25 set. 2020.

GARCIA, Ana Letícia Guimarães. Manual de Percepção visual: teoria e psicologia das cores. São Paulo, Unip, 2020.

GERICKE, Gerda. 1937: Bombardeio de Guernica. Deutsche Welle (DW). Disponível em: https://www.dw.com/pt-br/1937-bombardeio-de-guernica/a-800994. Acesso em: 28 set. 2020.

HISTORY. Guernica, de Pablo Picasso, retorna para a Espanha após quatro décadas. https://history.uol.com.br/hoje-na-historia/guernica-de-pablo-picasso-retorna-para-espanhaapos-quatro-decadas. Acesso em: 21 set. 2020.

HODGE, Susie. Breve história da arte moderna. Trad. Julia da Rosa Simões. São Paulo: Gustavo Gili, 2019.

LADIC, Sylvia. Analyse d'oeuvre: Guernica de Pablo Picasso. Disponível em: http://ecours-arts-plastiques.com/analyse-doeuvre-guernica-de-pablo-picasso/. Acesso em: 21 de set. 2020. 
LESSER, Casey. The Guernica Effect: The Power and Legacy of Picasso's Guernica. (2011). Undergraduate Honors Theses. 2011. 160p. https://scholarworks.wm.edu/honorstheses/376. Acesso em: 03 abr. 2021.

LUSA. O caminho até Guernica para fazer no Museu Rainha Sofia. Diário de Notícias. em: https://www.dn.pt/artes/o-caminho-ate-guernica-para-fazer-no-museu-rainha-sofia5767858.html. Acesso em: 21 set. 2020.

MARTINS, Simone. O 3 de maio de 1808 em Madrid, Francisco de Goya. Disponível em: https://www.historiadasartes.com/sala-dos-professores/o-3-de-maio-de-1808-em-madrifrancisco-de-goya/. Acesso em: 05 out. 2020.

MOZER, Mariana Calvo. Touradas, toureiros e morte. Dissertação (mestrado em letras). Universidade Presbiteriana Mackenzie, São Paulo, 2011. Disponível em: http://tede.mackenzie.br/jspui/bitstream/tede/2113/1/Mariana\%20Calvo\%20Mozer.pdf. Acesso em: 02 out. 2020.

MUSEO NACIONAL REINA SOFIA. Guernica. Disponível em: https://www.museoreinasofia.es/coleccion/obra/guernica. Acesso em: 21 set. 2020.

MUSEO NACIONAL REINA SOFIA. Guernica as a political symbol. Disponível em: https://guernica.museoreinasofia.es/en/story/guernica-political-symbol. Acesso em: 28 set. 2020.

PARIS JOURNAL. Les arts. 15 mai 1914. Disponível em: http://obvil.sorbonneuniversite.fr/corpus/apollinaire/html/apollinaire_paris-journal.html. Acesso em: 25 set. 2020.

PARRAGON BOOKS. História da arte: arquitetura, pintura, escultura, artes gráficas, design. Bath, UK: Parrogon Book, 2012.

PROENÇA, Graça. História da Arte. São Paulo: Ática, 2014.

ROBINSON, Lynn. Picasso, Guernica. Disponível em: https://www.khanacademy.org/humanities/art-1010/cubism-earlyabstraction/cubism/a/picasso-guernica. Acesso em: 30 set. 2020.

RUBIO, José María Garzón. El toro en las artes y Picasso. Disponível em: http://servicios.diariosur.es/picasso/toros2.htm. Acesso em: 02 out. 2020.

UNITED NATIONS. Replica Tapestry of Pablo Picasso's "Guernica". Disponível em: https://www.unmultimedia.org/s/photo/detail/653/0065374.html. Acesso em: 28 set. 2020.

WIKIPEDIA. Exposição Universal de 1937. Disponível em: https://pt.wikipedia.org/wiki/Exposi\%C3\%A7\%C3\%A3o_Universal_de_1937. Acesso em: 25 set. 2020 . 